\title{
THE FUTURE OF EDUCATION IS ETHICAL. SOME CONSIDERATIONS ON THE ROLE OF ESP COURSES IN TRANSMITTING VALUES AND VIRTUES IN HEIS
}

\author{
Roxana NISTOR, PhD. \\ Babeș-Bolyai University Cluj-Napoca, Faculty of Letters, Romania \\ roxana.nistor@ubbcluj.ro
}

\begin{abstract}
Teaching has always been an ethical profession (Fisher, 2013; Campbell, 2000), and given the globalised world we are living in and the highly globalised labour market, instructors' mission is no longer to prepare students for local jobs only, but for international jobs as well. Therefore, the subjects taught in Higher Education Institutions (HEI) should not only prepare students for using specialised knowledge (hard skills) in specific professional contexts, but they should also instil values and virtues - those soft skills that are also essential on the (international) labour market. Consequently, ethical communication (which heavily relies on values and virtues) has become a pillar (Monteiro, et al., 2018) in higher education studies, as it plays an outstanding role in the teaching process and in making sure that students - as future young graduates - have a strong work ethic. As such, our article focuses on how ESP courses taught at the Faculty of European Studies within Babeș-Bolyai University (Romania) can help students acquire not only the specialised vocabulary in English necessary for their field of study, but also the values and virtues required for an appropriate work ethic and the ability to put themselves in other people's shoes when faced with an ethical dilemma to make sure that their solution maximizes the benefits of everyone involved.
\end{abstract}

Keywords: soft skills, ethical communication, higher education, values \& virtues, ESP.

\section{Introduction}

Education plays an outstanding role in both the personal and professional development of individuals, that is why different types of investments should be made in this field. Financial investments are obviously highly important in higher education institutions (HEI); however, money is not the only element that is essential in making sure that the educational process is carried out smoothly and successfully: values and virtues (and, therefore, ethical communication) should also be transmitted/taught to students to make sure that they acquire not only the hard skills and 
specialised knowledge necessary for their specific field of study, but also the soft skills that are also essential on the (highly international) labour market.

This pandemic and the last year and a half have shown us how fragile human connections can be and how important interpersonal relations and soft skills are for keeping in touch with colleagues, co-workers, or business collaborators. An article published in the online edition of Forbes Magazine mentions some of the ways in which the pandemic has reshaped our workplaces (Goldgrab 2021). Among these, the "habits of strategic thinking and of expanding networks" rank among the most important things that the labour market has lost, while "greater work expectations at the cost of self-care" have increased. The future of work is uncertain as the pandemic is not over, and it is very hard to tell for sure what is to come. As such, it is highly important that attention be given to interpersonal relations and those soft skills that can recreate the lost networks and (re)shape the workplace - whether physical or virtual -, among which adaptability, empathy, (work) ethic, cooperativeness, and responsibility.

According to those who advocate for Sigmund Freud's theories, all these values and virtues are acquired in early childhood (Wright 2019, p. 508); however, there are many other scholars (such as followers of Socrates', Piaget's, or Kohlberg's theories - which state that there are different phases at which various values and virtues are acquired depending on the individual's stage of development) who believe that these values and virtues can be identified and practiced throughout one's life (Wright 2019, p. 508). As such, the purpose of this article is to show that values and virtues can be acquired in early adulthood as well, that ethical communication relies on having/acquiring such values and virtues, and that they are extremely important to prepare graduates for the labour market, to help them build an appropriate work ethic, to support them in making appropriate decisions when faced with ethical dilemmas, all through an English for Specific Purposes (ESP) course taught at the Faculty of European Studies within Babeș-Bolyai University.

\section{Soft Skills, Ethical Communication, and ESP Courses}

Though the object of each of these subjects is different, they can actually be connected to one another. One of the roles of higher education institutions is to equip students with the necessary knowledge and skills that are required on the labour market. As such, their work ethic, their ability to communicate ethically and to make ethical decisions when faced with ethical dilemmas in 
school-related or business-related situations can be classified as soft skills that can be learnt (or taught) at university through an English for Specific Purposes (ESP) course as well.

The COVID-19 pandemic has led to the increasing use of computers, to working from home or studying from home, which, in their turn, have led to a lack of human connection and a 'soft skills drain', which was easily spotted, for instance, in the way 1 st -year students at the Faculty of European Studies collaborated (or, to be more precise, did not collaborate) during the past academic year of online courses. A 2019 LinkedIn Global Trends Report identified four trends for the future of work (and the pandemic has confirmed our need for them), namely soft skills, antiharassment practices, work flexibility, and pay transparency (LinkedIn 2019). Another 2019 report drafted as a result of a Strategic Partnership for Higher Education project, by the University of Pisa, the University of Latvia, Miguel Hernandez University, P. Porto ISCAP, and ERREQUADRO, also identified the most important skills that employers think university graduates should have, among which "willingness to learn, flexibility, knowledge in a specific technical area, teamwork and interpersonal relationships", as well as "motivation, enthusiasm, responsibility, humbleness" (Araujo et al. 2019, p. 8). If one looks at all the skills mentioned so far, which were essential in 2019, one can easily identify that most of them are soft skills, and, given the 'soft skills drain' caused by the current pandemic, working towards (re)achieving them has become a necessity, even more so as a 2019 Deloitte report even forecasts that, by 2030, two thirds of jobs will be human skill intensive, as "skills, as opposed to titles or degrees, will be the job currency of the future" (Deloitte 2019, p. 3).

Soft skills are very hard to define, but most studies emphasize the fact that they are essential (Goleman 1995; 1998; 2015; Hawkins \& Wintern 1995; Dell'Aquila, et al. 2017; Deming 2017; 2021). Also referred to as 'people skills' or 'transferable skills', soft skills represent an important part of what makes a graduate 'employable' (Clarke 2018, p. 1926). Because they are so hard to define, there is no exact list of what represents a soft skill, but it can include (without being limited to) empathy and emotional intelligence, (work) ethic, integrity and ethical responsibility, adaptability and resilience, self-motivation, mindfulness (Lau 2021). Not only do graduates need different specialised skills, but they also need individual attributes, and these can be acquired early in childhood (through the education they receive from their parents), as well as through (primary, secondary, tertiary) education. 
These soft skills heavily rely on a graduate's 'identity' (Holmes, 2013, p. 549). This identity can be developed through - and then defined by - the values and virtues students acquire. Values and virtues help one communicate ethically, as they "make us the persons we are" and they "provide the foundation of both ethical living and success in business" (Solomon 1999, p. xvi).

But what does 'to communicate ethically' mean? Put simply, ethical communication refers to "the application of ethical thinking to situations involving human communication" (Neher 2020, p. 7). Ethical thinking can be developed through the study of philosophy, and, more specifically, by studying ethical theories (such as the Divine Command Theory, the Ethical Egoism Theory, the Utilitarianist Theory, the Categorical Imperative, Virtue Ethics, or the Ethics of Care). However, this can prove to be a difficult achievement in an ESP course, as the purpose of such courses is to teach specialised vocabulary, to help students "use English in a particular domain" (Paltridge \& Starfield 2013, p. 2). Nonetheless, real-life case studies, authentic articles/materials, and educational games can be used in an ESP course so that students acquire the necessary knowledge, as well as the values and virtues that can help them think ethically, communicate ethically, and make ethical decisions in business-related situations.

\section{Learning how to Communicate Ethically with the Help of an ESP Course}

As previously mentioned, the role of HEIs is to prepare students for the labour market. This preparation or formation, however, which is done by each professor in their area of expertise, does not mean the mere transmission of specialised knowledge, because, as we have already seen, employers require a whole range of skills, among which the soft skills that are highly appreciated on today's increasingly international labour market.

As such, for instance, an ESP instructor - who already has numerous roles to play, such as those of needs assessors, syllabus designers, authentic materials developers and contentknowledgeable instructors (Belcher 2006, p. 135) - must take on another essential role to fight this 'soft skills drain' caused by the current pandemic, namely that of a coach or mentor, that of 'instiller' of values and virtues. We have already seen that values and virtues are essential for business success, but they are also of utmost importance in crisis communication when "choosing the right words can be one of the best strategies in dealing with crises" (Nistor-Gâz 2021, p. 141), since "the spiral of violence begins as a spiral of distorted communication that leads through the spiral of uncontrolled reciprocal mistrust, to the breakdown of communication" (Borradori 2003, 
p. 19). Therefore, students should learn how to communicate correctly not only to avoid the spiral of violence, but also to avert personal/business conflicts and misunderstandings, which, in many cases, are the result of the inappropriate transmission of ideas, opinions, and thoughts.

Communication - whether written or spoken, verbal or non-verbal - is at the centre of an ESP course, as the current approach to language teaching and learning is the communicative one, since the communicative competence is an interactive competence (Habermas 1983, p. 190), meaning that students have the opportunity of practising their speaking and writing skills to improve their communication skills in English. Introduced in 1972 by Hymes, the communicative competence approach to language teaching and learning focuses on four components: linguistic, socio-linguistic, linguistic, and strategic. All these four components help students use a foreign language (English in our case) "for a range of different purposes and functions, (...) according to the setting and the participants (...), to produce and understand different types of texts (...), and to maintain communication despite having limitations in one's language knowledge" (Richards 2006, p. 3).

Given that the words can make or break a deal, students should be prepared to use language appropriately. As previously mentioned, this article focuses on offering a general perspective on how ESP courses taught to $1^{\text {st }}$-year students enrolled at the Faculty of European Studies, which offers BA programmes in International Relations and European Studies, Diplomacy in Business, European Administration, and Management, help students use English correctly and ethically in various contexts. The specificity of each of the aforementioned BA specialisations shows how important it is to be able to send correct messages, but also how essential ethical communication is, i.e. how decisions are made, if they take into account the people involved and the consequences of their words and/or actions, and if the message is tailored according to the audience.

As previously mentioned, ethical communication relies heavily on one's vales and virtues, more specifically on their character and education. According to Professor Robert Solomon, some of the most important virtues that are required in the business world range from acceptance and tolerance to autonomy and cooperativeness, compassion, fairness, honesty, integrity, loyalty, and responsibility, just to mention a few (Solomon 1999). These are - we believe - the virtues that ESP instructors teaching at the Faculty of European Studies can instil in their students through the topics they choose to teach, as well as through the activities they carry out with their students in the classroom. 
Let us take the example of $1^{\text {st }}$-year students studying International Relations and European Studies (in Romanian, English, or German) at the Faculty of European Studies. The syllabus elaborated by the ESP instructor and endorsed by the Language Department contains topics related to the curriculum of their specialisation. For instance, in their $1^{\text {st }}$ year of studies, the Faculty of European Studies offers courses in the History of European Integration, Introduction to International Relations, Institutional Communication, Political Science, etc. In the $2^{\text {nd }}$ year, the curriculum contains subjects covering Decision-making in the E.U., European Law, Negotiation and Mediation in International Relations, Political Ideologies, etc. In their last year of studies, the International Relations and European Studies specialisation offers students courses in Foreign Policy and Democracy, International Conflicts, International Relations Theories, EU Governance, Global Issues, etc. Consequently, the syllabus for the ESP course is built so that students learn the specialised vocabulary they can use to facilitate the reading of the necessary bibliography, to write papers/deliver presentations on specific domain-related topics, to prepare them for jobs in their field of study and not only. As such, the ESP course syllabus includes, for the first semester, topics related to these subjects, such as: Unit 1. Communication. Unit 2. Cultures, Unit 3. Human Rights Discrimination. War and Peace, Unit 4. Languages in the E.U., Unit 5. International Relations. The second semester syllabus is a bit more specialised, in that it covers vocabulary and activities that focus on Politics and Elections (Unit 1), Misconduct (Unit 2), Responsibility (Unit 3), Law (Unit 4), and Academic Writing (Unit 5). Through all the topics chosen in the syllabi for the ESP courses, students can improve their English language skills, their presentation skills, or their writing skills, but they can also acquire and/or develop some (already existing) values and virtues, which are necessary for ethical communication and responsibility on the labour market irrespective of the career they are going to choose. Let us take some examples.

The virtues of empathy, compassion, and tolerance can be instilled into students in the first semester through the unit on Cultures. ESP courses always start with the reminders that the ESP course is a safe place, where students can speak freely, without being laughed at for the ideas they express or the language mistakes they make, that, when expressing personal opinions, there is no right or wrong answer - on condition that what students say does not hurt someone else's feelings - , and that "one's freedom ends where someone else's begins." Through these reminders, the virtue of acceptance is practised. This paves the way for the actual unit related to cultural diversity, cultural awareness, and interculturality. Next, using Pearson Macmillan's Market Leader $3^{\text {rd }}$ 
edition book series (2010) as a starting point, the first part of this unit includes some icebreaking speaking activities where students are encouraged to discuss a quotation ("When overseas, you learn more about your own country than you do about the place you are visiting", Clint Borben, American activist) and to answer questions related to cultural diversity and cultural uniformity, (business) etiquette across cultures, this way learning to understand that people are different not only in the way they look, but also in the way they act and live, as well as to become more tolerant towards cultures they are not that familiar with or that they do not understand very well. Students can also deliver presentations in English about a culture of their choice, that they are passionate or curious about to learn more things about them or to raise their colleagues' awareness of that culture. In terms of grammar and ethical communication, this unit focuses on the usage of modal verbs, used to express advice, obligation, and necessity. Since words "carry not only sound but intention" (Abu Jaber 2001, p. 49), modal verbs help English speakers sound more polite, and they are widely used in diplomatic language as well to make an order or a command sound softer, to transmit information in a more diplomatic manner. Furthermore, students practice the usage of modal verbs to formulate polite requests for clarifications, for checking information, or for asking for further information.

These virtues of empathy, compassion, and tolerance can be practised further through Unit 3. Human Rights. Discrimination. War and Peace. In this unit, students learn that human rights are inalienable, inherent in all human beings, universal, and egalitarian. These terms are not only part of the specialised vocabulary that students have to study and remember, but this way students also learn (or are reminded that) all people have the same rights irrespective of their race, ethnicity, social or marital status, etc. Furthermore, the unit also includes authentic press articles that discuss diversity in different countries, and this is again a fertile ground for speaking activities where students not only practise their speaking and grammar skills, but they also express opinions about various situations, this way paving the way for heated or interesting debates about cultural differences or stereotypes. By mediating these debates, the ESP instructor can raise students' awareness of errors in communication, politically correct language, diplomatic language, or traits that show good character and that are desirable on the labour market.

Other virtues that are valued and required by employers on the labour market and that can be taught or practised through an ESP course are fairness, honesty, integrity, and responsibility. For instance, in the second semester, the first unit discussed in our ESP class is related to Politics 
and Elections. In terms of vocabulary and grammar, this unit (re)introduces students to the usage of adjectives and their degrees of comparison. In terms of ethical communication and values and virtues, this unit is a fruitful opportunity for students to discuss character since character is the basis of Virtue Ethics, which is a "type of moral theory [that] is all about becoming a certain kind of person" (Hodgins \& Shrives 2011, p. 151). Consequently, students express their opinions about the politicians of today and of the past, using the adjectives introduced in this unit, and try to define the ideal politician that they themselves would vote for. This way, the virtues of fairness, honesty, integrity, and responsibility come into play and students discover how important they are for the well-being of all citizens.

In terms of ethical communication, this unit is a fertile ground for the acquisition and practice of elements pertaining to the Utilitarian theory, which is a moral consequentialist theory according to which "human beings ought to act in the interests of all those concerned" (Hodgins \& Shrives 2011, p. 115) and that, as its name suggests, focuses on the consequences of one's actions, on their usefulness. More clearly, by applying this moral theory, students learn how to express ideas and opinions and act in a way that does not harm or hurt their interlocutors. They can do this by using:

- modal and semi-modal verbs (e.g.: can/could, may/might, shall/should, ought to, be able to) - as previously mentioned, modal verbs can soften a sentence, an order, a command, an opinion;

- impersonal expressions (e.g.: it seems, it appears...) - these expressions can also help the speakers distance themselves from the utterances; therefore, there is less personal involvement;

- passive voice - the Passive Voice helps the speaker distance themselves by putting an emphasis on the outcome of an action and not on who performed the action;

- qualifiers (e.g.: unfortunately, I'm afraid, actually, to be honest) - used at the beginning of the sentence they can soften the message that follows;

- negative question forms (e.g.: instead of saying 'They should be punished' - which is a very strong and emotionally charged, one could say 'Shouldn't they be punished?') 
- they are widely used to make suggestions, this way softening the message that is transmitted ${ }^{1}$.

Furthermore, through the activities prepared for them - either group, pair, or individual activities -, students also learn how to organise the tasks received and how to manage the time allocated to them, therefore they learn/practise the virtues of autonomy and cooperativeness. For example, in the fourth unit studies in the second semester (Law), one of the activities assigned to students is to work in groups, to pretend that they are members of a jury and reach a verdict in six different cases. As such, by presenting arguments and by using legal words and phrases, students are asked to cooperate and discuss so that they find a legal and ethical solution to the cases given.

All these values and virtues that students acquire or further develop through the topics discussed and the activities carried out in the ESP classroom are of utmost importance for the personal and professional development of students who, as young graduates, will have to work in and adapt to various situations on the labour market. Since jobs today involve working with a (usually large) group of various individuals (each with their own character and acquired or inexistent personal and professional values and virtues, each (probably) from various cultural backgrounds), which automatically leads to various difficult or hard to manage situations, having acquired and then practised values and virtues that are necessary on the labour market helps students be able to communicate ethically according to the decision they are faced with and to make ethical decisions in difficult situations that involve ethical thinking.

\section{Conclusions}

Today's international labour market requires that employers and employees work with people from different cultures, each with their own set of values and virtues, which, in many situations, if not used or are misinterpreted, can lead to conflict or crisis situations. Not only is English the main language of international communication, but it is also the language that many people have to use properly to tailor and send a message in various job-related situations. In these cases, it is highly important that voice be given to values and virtues, which lay the foundation for ethical communication, i.e. to applying ethical thinking to real-life communication situations in

\footnotetext{
${ }^{1}$ For more details on communication techniques in formal settings, see Delia Pop-Flanja, Communication for International Careers 1, Cluj-Napoca, Presa Universitară Clujeană, 2021.
} 
order to maximise the benefits of as many of the people involved and to minimise the harms (the Utilitarian theory), and to act as a virtuous person would act (Virtue Ethics) without using people as means to reach an objective (the Categorical Imperative).

Although students do not learn about these theories specifically - since they are not the main objective of the ESP course -, through the activities prepared for and carried out in the ESP class, they can acquire and/or further develop some values and virtues that are required on the labour market according to several reports that have been previously mentioned, such as acceptance, tolerance, autonomy, cooperativeness, compassion, fairness, honesty, integrity, loyalty, or responsibility. Using these values and virtues, they can become virtuous people, successful managers or leaders, they can easily pay attention to the words and phrases they use, they can make sure that their discourse is adapted to their audience and the words they use are tactful enough in order not to cause harm or conflicts.

The current pandemic has affected the way in which people interact with each other, there is what we call a 'soft skills drain,' and this drain can be stopped by making sure that instructors in primary, secondary, and tertiary education focus the object of their subjects not only on hard skills, but on soft skills as well, helping students acquire and develop their values and virtues. It is said that 'No man is an island,' and this pandemic has shown us exactly that - that we need human connection, that we need empathy, that we need to collaborate, that we need to create bridges between cultures.

\section{References}

1. Abu Jaber, K. S., 2001. Language and Diplomacy. In: J. Kurbalija \& H. Slavik, eds. Language and Diplomacy. Msida: DiploProjects, pp. 49-54.

2. Anon., n.d. Ulysse Soft Skills for Employability. [Online] Available at: https://ulisseproject.eu/ [Accessed 21 July 2021].

3. Araujo, M. et al., 2019. Survey Data presentation. ULISSE I02 Soft Skills Report 1. [Online] Available at: https://ulisseproject.eu [Accessed 16 August 2021].

4. Belcher, D. D., 2006. English for Specific Purposes: Teaching to Perceived Needs and Imagined Futures in Worlds of Work, Study, and Everyday Life. TESOL Quarterly, 40(1), pp. 133-156. 
5. Borradori, G., 2003. Philosophy in a Time of Terror. Dialogues with Jürgen Habermas and Jacques Derrida. Chicago and London: The University of Chicago Press.

6. Campbell, E., 2000. Professional Ethics in Teaching: Towards the Development of a Code of Practice. Cambridge Journal of Education, 30(2), pp. 203-221.

7. Clarke, M., 2018. Rethinking graduate employability: the role of capital, individual attributes and context. Studies in Higher Education, 43(11), pp. 1923-1937.

8. Dell'Aquila, E. et al., 2017. Educational Games for Soft-Skills Training in Digital Environments. Switzerland: Springer.

9. Deloitte, 2019. Premium Skills. The wage premium associated with human skills, Sydney: Deloitte Access Economics.

10. Deming, D. J., 2017. The Growing Importance of Social Skills in the Labour Market. The Quarterly Journal of Economics, 132(4), pp. 1593-1640.

11. Deming, D. J., 2021. National Bureau of Economic Research Working Paper Series. [Online] Available at: http://www.nber.org/papers/w28733[Accessed 21 July 2021].

12. Fisher, Y., 2013. Exploration of Values: Israeli Teachers' Professional Ethics. Social Psychology of Education, 16(2), pp. 297-315.

13. Goldgrab, S., 2021. Forbes. [Online] Available at: https://www.forbes.com/sites/forbescoachescouncil/2021/07/08/five-ways-the-pandemicchanged-the-workplace/ [Accessed 15 August 2021].

14. Goleman, D., 1995. Emotional Intelligence. New York: Bantam.

15. Goleman, D., 1998. Working with Emotional Intelligence. New York: Bantam.

16. Goleman, D., 2015. What Makes a Leader?. In: On Emotional Intelligence. Boston, Massachusetts: Harvard Business Review Press, pp. 1-22.

17. Habermas, J., 1983. Cunoaştere şi comunicare. Bucureşti: Editura Politică.

18. Hawkins, P. \& Winter, J., 1995. Skills for Graduates in the 21st Century. Cambridge: Association of Graduate Recruiters.

19. Hodgins, M. \& Shrives, P., 2011. Business Ethics and Corporate Governance. 1st ed. Harlow: Pearson Education Limited.

20. Holmes, L., 2013. Competing perspectives on graduate employability: possession, position or process?. Studies in Higher Education, 38(4), pp. 538-554. 
21. Lau, Y., 2021. Soft Skills Are Essential To The Future Of Work (Forbes Magazine). [Online] Available at: https://www.forbes.com/sites/forbeshumanresourcescouncil/2021/01/20/soft-skills-areessential-to-the-future-of-work/ [Accessed 16 August 2021].

22. LinkedIn, 2019. 2019 Global Talent Trends. [Online] Available at: https://app.box.com/s/c5scskbsz9q6lb0hqb7euqeb4fr8m0bl/file/388525098383 [Accessed 16 August 2021].

23. Monteiro, F., Leite, C. \& Rocha, C., 2018. Ethical Education as a Pillar of the Future Role of Higher Education: Analysing its Presence in the Curricula of Engineering Courses. Futures, Volume 111, pp. 168-180..

24. Neher, W. W., 2020. Communicating Ethically. Character, Duties, Consequences, and Relationships. New York and London: Routledge.

25. Nistor-Gâz, R.-M., 2021. Some Considerations on Teaching Ethicl Communication in an ESP Class. A First Step towards Improved International Crisis Communication. In: D. PopFlanja, ed. Crisis Communication and Conflict Resolution (1st edition). Cluj-Napoca: Presa Universitară Clujeană, pp. 139-147.

26. Paltridge, B. \& Starfield, S., 2013. The Handbook of English for Specific Purposes. Boston: Wiley-Blackwell.

27. Pop-Flanja, D., 2021. Communication for International Careers 1. Cluj-Napoca: Presa Universitară Clujeană.

28. Richards, J. C., 2006. Communicative Language Teaching Today. 1st ed. Cambridge, New York, Melbourne, Madrid, Cape Town, Singapore, Sao Paolo: Cambridge University Press.

29. Solomon, R. C., 1999. A Better Way to Think about Business. How Personal Integrity Leads to Corporate Success. New York, Oxford: Oxford University Press.

30. Wright, D. K., 2019. Communication Ethics. In: D. W. Stacks, M. B. Salwen \& K. C. Eichhorn, eds. An Integrated Approach to Communication Theory and Research. New York: Routledge, pp. 505-515. 